\title{
PENGUKURAN NILAI INDUKTANSI PELAT ALUMINIUM BERDASARKAN VARIASI KAPASITANSI MENGGUNAKAN MODUL EVB LDC 1000
}

\author{
Cinryani*, Lazuardi Umar, Salomo, Maksi Ginting \\ Jurusan Fisika Fakultas Matematika dan Ilmu Pengetahuan Alam Universitas Riau \\ *E-mail korespondensi: ncinryani@yahoo.com
}

\begin{abstract}
The method that has been done in metal thickness measurement is a plate thickness measurement method using an eddy current based sensor. Eddy current sensors can measure the thickness of non-magnetic metal layers through an inductance relationship with variations in thickness where the thickness used for $\mathrm{Cu}$ is $0.4 \mathrm{~mm}, 0.9 \mathrm{~mm}, 1.5 \mathrm{~mm}, 2 \mathrm{~mm}, 4 \mathrm{~mm}$, while Al is used ie $0.4 \mathrm{~mm}, 0.5$ mm, $1 \mathrm{~mm}, 1.2 \mathrm{~mm}, 1.5 \mathrm{~mm}, 1.8 \mathrm{~mm}, 2 \mathrm{~mm}, 2.2 \mathrm{~mm}, 4 \mathrm{~mm}, 5 \mathrm{~mm}$ with a single frequency of $1 \mathrm{~Hz}$ with a capacitance value of $C_{0} 5 \mathrm{pF}$. The inductance vs. thickness curve for aluminum and copper has an exponential relationship. The distance between the sensor and non-magnetic material is kept constant at $2 \mathrm{~mm}$. Variations in the value of capacitance CO used in the measurements are then varied to $100 \mathrm{pF}, 200 \mathrm{pF}$, and $300 \mathrm{pF}$ to see the effect of inductance on the thickness of the plate as a function of the capacitor $(C)$ oscillation.
\end{abstract}

Keywords: Sensors, Flat Coils, Evaluation module of LDC 1000 board, Eddy current, Copper, Aluminum

\begin{abstract}
ABSTRAK
Metode yang telah dilakukan dalam pengukuran ketebalan logam adalah metode pengukuran ketebalan pelat menggunakan modul EVB TI LDC 1000 dengan sensor berbasis eddy current.Sensor eddy current dapat mengukur ketebalan lapisan logam non magnetik melalui hubungan induktansi dengan variasi ketebalan dimana ketebalan yang digunakan untuk $\mathrm{Cu}$ yaitu $0,4 \mathrm{~mm}, 0,9 \mathrm{~mm}, 1,5 \mathrm{~mm}, 2 \mathrm{~mm}, 4 \mathrm{~mm}$, sedangkan Al yang digunakan yaitu 0,4 mm, 0,5 mm, $1 \mathrm{~mm}$, 1,2 mm, 1,5 mm, 1,8 mm, $2 \mathrm{~mm}, 2,2 \mathrm{~mm}, 4 \mathrm{~mm}, 5 \mathrm{~mm}$ dengan frekuensi tunggal sebesar $1 \mathrm{~Hz}$ dengan nilai kapasitansi $C_{0} 5 \mathrm{pF}$. Kurva induktansi vs ketebalan untuk aluminium dan tembaga memiliki hubungan eksponensial. Jarak antara sensor dengan material non magnetik dijaga konstan sebesar $2 \mathrm{~mm}$. Variasi nilai kapasitansi $C_{0}$ yang digunakan dalam pengukuran kemudian divariasikan menjadi 100 pF, 200 pF, dan 300 pF untuk melihat pengaruh induktansi terhadap ketebalan pelat sebagai fungsi dari kapasitor $(C)$ osilasi.
\end{abstract}

Kata kunci: Sensor, Koil datar, Modul evaluation LDC 1000, Eddy Current, Tembaga, Aluminium

Diterima 04-09-2019 | Disetujui 15-01-2020| Dipublikasi 31-03-2020

\section{PENDAHULUAN}

Pendahuluan Ilmu pengetahuan menjadi dasar bagi perkembangan teknologi yang semakin canggih. Penelitian dilakukan secara teoritis dan eksperimental bertujuan sebagai penunjang kemajuan ilmu pengetahuan dan teknologi [1]. Kebutuhan sensor dan sistem sensor tidak hanya pada bidang industri, tetapi juga merambah pada bidang lain, seperti; bidang otomotif, teknologi pengolahan, bangunan, medis, komunikasi, teknologi informasi dan bidang lainya. Proses automatisasi industri menggunakan pengukuran yang sangat krusial dalam berbagai piranti elektromekanis dan mekatronik [3].

Sensor koil datar merupakan metode sederhana dengan biaya rendah dan 
mempunyai daya tarik yang masih terinspirasi untuk mengembangkan sensor koil datar dengan daya handal, kasar, dan mudah untuk menangani. Arus Eddy merupakan prinsip fisis yang digunakan pada sensor koil datar [4]. Penelitian ini dilakukan dengan menggunakan arus Eddy untuk mengetahui ketebalan logam non magnetik seperti aluminium dan tembaga.

Pengukuran menggunakan metode Eddy Current dapat digunakan pada bahan magnetik maupun non magnetik. Penelitian ini dilakukan dengan memvariasikan ketebalan pelat sampel (thickness, $\mathrm{t}$ ) logam non magnetik dengan frekuensi (f) tunggal. Aplikasi teknologi seperti pengukuran ketebalan pelat logam, pemeriksaan mutu barang, penambahan dan perawatan permukaan pelat kerja menggunakan prinsip kerja metode Eddy Current. Sensor Eddy Current berfungsi sebagai sensor induktif yang dapat digunakan pada bidang otomotif serta bidang automatisasi, baik untuk bidang industri atau untuk penggunaan sektor pribadi [2].

\section{TINJAUAN PUSTAKA}

\section{Sensor Koil Datar}

Sensor kumparan induksi disebut juga sensor koil. Sensor induktif dikenal memiliki ketahanan terhadap kondisi lingkungan. Sensor ini digunakan sebagai detektor dengan memanfaatkan sifat Eddy Currentpada objek ukur, terutama berkaitan dengan material non ferromagnetik.

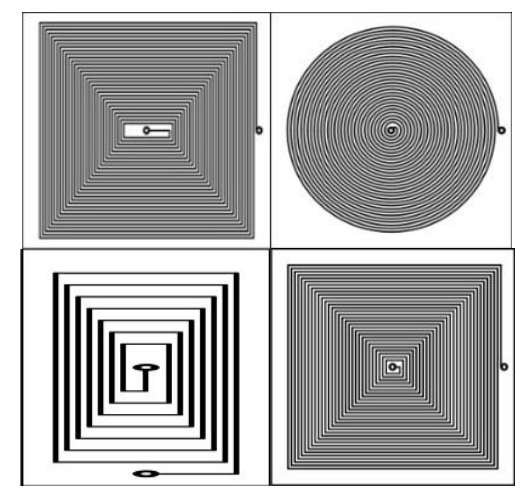

Gambar 1. Variasi geometri koil datar [7].
Variasi sensor koil datar dibedakan berdasarkan bentuk geometri yaitu berupa persegi panjang, lingkaran, persegi dan oktogonal. Variasi Elemen koil datar dapat dilihat pada Gambar 1.

Metode pengukuran yang digunakan diantaranya metode sensor induktif. Metode ini digunakan untuk mendeteksi sifat material logam tanpa harus menyentuh (contactless) menggunakan arus induksi dan koil inductordalam menghasilkan medan magnet yang memiliki frekuensi tinggi.

\section{Prinsip Kerja Sensor Koil Datar}

Suatu material konduktif atau objek pengganggu didekatkan pada medan magnetik maka akan melakukan induksi sejumlah kecil arus dalam material dan menghasilkan medan magnetik yang berlawanan dengan medan dari sensor. Interaksi antara kedua medan magnetik akan berubah jika terdapat jarak antara sensor dengan material pengganggu (target).

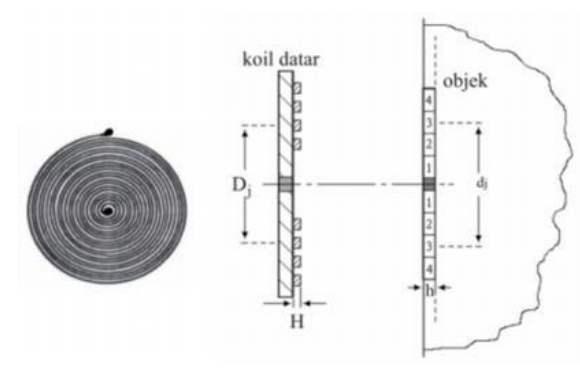

Gambar 2. Elemen koil datar didepan suatu bahan konduktor.

\section{Induktansi Diri (Self Inductance)}

Induktansi diri merupakan induksi magnetik suatu kumparan atau koil yang dialiri arus listrik (I) dan akan menimbulkan fluks magnetik $\phi$ disekitarnya. Menurut hukum Faraday, tegangan $\mathrm{v}$ yang diinduksi dalam kumparan sebanding dengan jumlah kumparan dan laju perubahan fluks magnetiknya $\phi$. Besar gerak gaya listrik $(\varepsilon)$ yang dihasilkan adalah:

$$
\varepsilon=-N \frac{d \Phi}{d t}=-N \frac{d}{d t} B A \operatorname{Cos} \theta
$$

\section{Induktansi Bersama (Mutual Inductance)}

Arus mengalir pada sebuah induktor 
menghasilkan induktansi diri yang dipengaruhi oleh adanya induksi magnetik luar sehingga menghasilkan induktansi bersama atau yang dikenalMutual Inductance. Menurut Hukum Faraday, besar ggl yang diinduksi kekumparan berbanding lurus dengan laju perubahan fluks yang melewatinya. Besar kedua mutual induksi ini sama sehingga dapat ditulis $M_{12}=M_{21}=M$.

Induktansi kedua induktor adalah :

$$
l_{1}=\frac{\mu_{0} \mu_{r} N_{1}^{2} A}{l} \text { dan } l_{2}=\frac{\mu_{0} \mu_{r} N_{2}^{2} A}{l}
$$

\section{Rangkaian Elektronika untuk Evaluasi Sensor Induktif}

Sensor induktif dikenal memiliki ketahanan terhadap kondisi lingkungan. Salah satu prinsip yang digunakan adalah memanfaatkan sifat Eddy Current pada objek ukur, terutama berkaitan dengan material non-feromagnetik.

\section{Rangkaian Osilator LC}

Osilator LC menggunakan rangkaian resonansi sebagai pembangkit gelombang dan menggunakan penguat untuk mengatasi redaman oleh resistansi dalam induktor dan konduktansi kapasitor.Dari sudut fasa $I_{m} Z=0$ ditentukan frekuensi resonansi $\omega_{0}$ menjadi:

$$
f=\frac{1}{2 \pi \sqrt{L C}}\left(1-\frac{1}{2 Q^{2}}\right.
$$

\section{Jenis Bahan Material}

\section{Aluminium}

Aluminium merupakan logam ringan dan memiliki ketahanan korosi yang baik, hantaran listrik yang baik dan sifat lainnya. Aluminium bersifat paramagnetik. Bahan paramagnetik adalah bahan yang resultan medan magnet atomis masing-masing atom tidak nol, tetapi resultan medan magnet atomis total seluruh atom dalam bahan nol [10].Permeabilitas bahan paramagnetik adalah $\mu>\mu_{0}$ dan suseptibilitas magnetik bahannya $0>m \chi$.
Aluminium umumnya dicampur dengan logam lainnya sehingga membentuk aluminium paduan. Material ini dimanfaatkan bukan saja untuk peralatan rumah tangga, tetapi juga dipakai untuk keperluan industri, kontsruksi, dan lain sebagainya.

\section{Tembaga}

Semua senyawa Tembaga bersifat diamagnetik dan tidak berwarna (kecuali $\mathrm{Cu}_{2} \mathrm{O}$ yang berwarna merah), sedangkan semua senyawa Tembaga (II) bersifat paramagnetik dan berwarna. Tembaga bersifat racun bagi makhluk hidup. Tembaga $(\mathrm{Cu})$ merupakan unsur yang jarang ditemukan di alam (precious metal). Logam Tembaga yang memiliki koduktivitas elektrik tinggi sering digunakan sebagai kawatpenghantar listrik [5].

\section{Modul Evaluation Board LDC 1000}

Modul evaluation board LDC 1000 merupakan salah satu teknologi sensor induktif yang dirancang untuk mendeteksi dan mengukur keberadaan, posisi, atau komposisi dari suatu material konduktif. Aplikasi dari penggunaan teknologi sensor induktif ini semakin berkembang di beberapa bidang, seperti automotif, industri, kesehatan, otomatisasi, komunikasi dan lainnya [8].

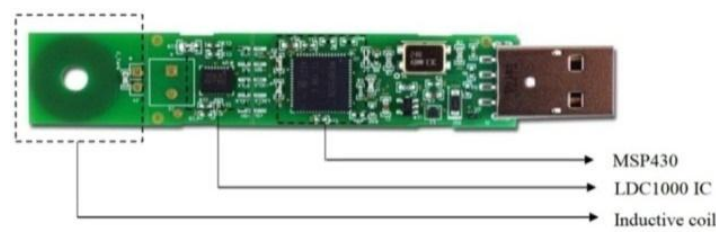

Gambar 3. Bagian-bagian sensor koil datar menggunakan modul evaluation board LDC 1000 [11].

\section{METODE PENELITIAN}

Metode Eksperimen ini dilakukan di Laboratorium Fisika Terapan Bidang Minat Instrumentasi Jurusan Fisika Fakultas Matematika dan Ilmu Pengetahuan Alam Universitas Riau. Tahapan-tahapan pengukuran ketebalan pelat material non magnetik $\mathrm{Al}$ dan $\mathrm{Cu}$ menggunakan sensor koil 
datar yang dievaluasi dengan modul Evaluation Board LDC 1000 yaitu;

\section{Set Up Eksperimen}

Pengukuran ketebalan pelat dimulai dari pembuatan prototipe pengukuran ketebalan pelat non magnetik dimulai dari karakterisasi sensor koil datar yang telah didesain dengan perangkat lunak Eagle. Pengukuran dilakukan dengan memvariasikan ketebalan pelat yang dinyatakan sebagai $\mathrm{t}$ (thickness). Variasi ketebalan pelat sampel (t) antara $0,1 \mathrm{~mm}$ sampai $10 \mathrm{~mm}$ dikalibrasi menggunakan carbon fiber composites digital thickness gauge, jarak antara sensor koil datar terhadap pelat (d) dibuat konstan dengan ketebalan pelat yang berbeda-beda. Evaluasi pengukuran nilai $\mathrm{L}$ akibat ketebalan pelat non magnetik (t) diolah dengan modul LDC 1000 EVM GUI yang selanjutnya diolah menggunakan program SigmaPlot.

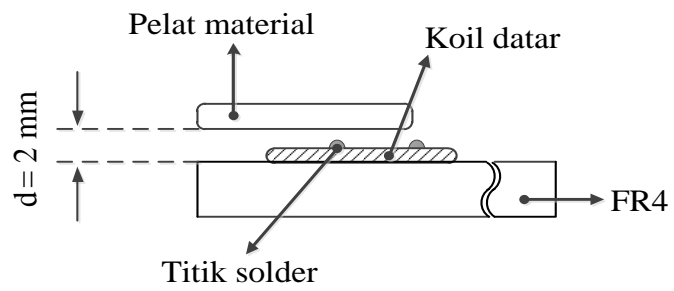

Gambar 4. Desain jarak antara sensor koil datar dengan pelat.

\section{Karakterisasi Sensor Koil Datar}

Sensor induktif berupa pelat koil datar yang dikembangkan menggunakan teknologi Printed Circuit Board (PCB) mampu mendeteksi jarak translasi yang sangat kecil bahkan kurang dari orde $0,5 \mathrm{~mm}$. Pembuatan sensor koil datar built in dipesan di perusahaan Spectra Bandung yang mampu membuat PCB dengan resolusi minimum $10 \mathrm{mil}(0.254 \mathrm{~mm})$.

\section{Pengukuran Ketebalan Pelat dengan Sensor Eddy Current}

Pengukuran ketebalan pelat dilakukan menggunakan sensor eddy current yang menghasilkan hubungan antara tegangan $\left(\mathrm{U}_{0}\right)$ dan frekuensi (f). Sensor eddy current dengan material penggangu dibuat dengan jarak konstan (d) menggunakan rangkaian osilator LC sehingga akan memperoleh frekuensi keluaran.

\section{Variasi Jarak Koil dengan Pelat}

Pengukuran dilakukan menggunakan dua pelat non magnetik yaitu aluminium $(\mathrm{Al})$ dan tembaga $(\mathrm{Cu})$. Variasi ketebalan dari masingmasing pelat yang berbeda dibuat jarak konstan yang bervariasi. Variasi jarak koil dengan pelat dilakukan pengukuran dengan menggunakan nilai kapasintasi sebesar $5 \mathrm{pF}$. Jarak koil dengan pelat yang konstan divariasikan yaitu $0,4 \mathrm{~mm}, 0,5 \mathrm{~mm}, 152 \mathrm{~mm}$, $1.5 \mathrm{~mm}, 1.8 \mathrm{~mm}, 2 \mathrm{~mm}, 2.2 \mathrm{~mm}, 4 \mathrm{~mm}$ dan 5 $\mathrm{mm}$. Pengukuran ketebalan dalam penelitian ini menggunakan koil berbentuk lingkaran yang telah dikarakterisasikan pada penelitian sebelumnya [9].

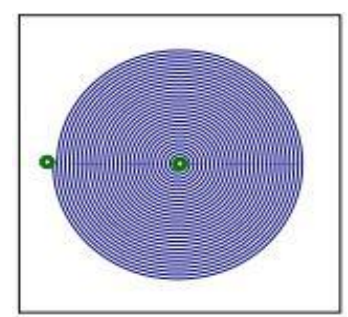

Gambar 5. Sensor koil datar berbentuk lingkaran.

\section{Variasi Nilai Kapasitansi $C_{0}$}

Koil datar masing-masing diuji menggunakan variasi nilai kapasitansi $\mathrm{C}_{0}$ pada keadaan suhu ruang $300 \mathrm{~K}$ menggunakan perangkat lunak LDC 1000 EVM GUI. Nilai kapasitansi $\mathrm{C}_{0}$ divariasikan dari yang terkecil adalah sebesar $100 \mathrm{pF}, 200 \mathrm{pF}$, dan $300 \mathrm{pF}$. Nilai kapasitansi $\mathrm{C}_{0}$ yang digunakan terkecil sebesar $100 \mathrm{pF}$ karena nilai kapasitansi ini merupakan nilai umum bawaan dari modul EVB LDC 1000 [6].

\section{Pemodelan dan Pengolahan Data}

Pengukuran dilakukan menggunakan modul EVB LDC 1000 menghasilkan nilai induktansi L kemudian diolah menggunakan SigmaPlot. Modul yang digunakan dilengkapi dengan perangkat lunak LDC 1000 EVM GUI yang 
merupakan program untuk menggerakkan segala fungsi pengukuran sensor koil datar [8].

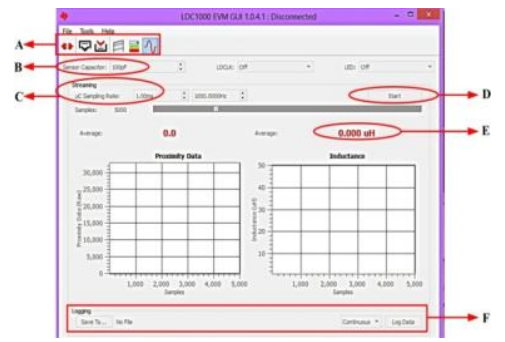

Gambar 6. Screensoot tampilan dasar perangkat lunak LDC EVM 1000.

Keterangan:
A. Icon toolbar
B. Set kapasitansi $\mathrm{C}_{0}$
C. Set waktu
D. Perintah mulai dan berhenti
E. Nilai induktansi $\mathrm{L}$
F. Penyimpanan data sampel

Modul evaluation boardterhubung ke komputer dengan menggunakan port USB, sehingga data diperoleh dan diolah ke komputer. Tampilan perangkat lunak LDC 1000 EVM GUI dapat dilihat pada Gambar 6.

\section{HASIL DAN PEMBAHASAN}

Variasi pengukuran ketebalan pelat non magnetik $\mathrm{Cu}$ dan $\mathrm{Al}$ dengan sensor koil datar menggunakan modul evaluation board LDC 1000 dilakukan dengan cara yaitu variasi nilai kapasitansi $\left(\mathrm{C}_{0}\right)$. Hasil pengukuran pada penelitian ini ditampilkan dalam bentuk grafik yang menggambarkan hubungan antara induktansi dengan ketebalan masing-masing pelat.

Pengaruh ketebalan pelat yang semakin tebal menyebabkan efek kulit yang artinya kerapatan Arus Eddy menurun secara eksponensial dimana kemampuan arus eddy menurun pada logam yang memiliki ketebalan yang besar. Semakin tebal pelat $\mathrm{Al}$ dan $\mathrm{Cu}$ maka konduktivitasnya semakin kecil dan hambatan semakin besar. Konduktivitas listrik suatu material mempengaruhi pengukuran dimana material memiliki masing-masing konduktivitas listrik tembaga $6 \times 10^{7}(\Omega / \mathrm{m})^{-1}$ dan alumunium $3,8 \times 10^{7}\left(\Omega / \mathrm{m}^{-1}[10]\right.$.

\section{Hasil Pengukuran dengan Variasi Nilai Kapasitansi $\mathbf{C}_{0}$}

Pengaruh nilai kapasitansi pada pengukuran ketebalan diuji dengan memvariasikan nilai kapasitansi $\mathrm{C}_{0}$, yaitu sebesar $100 \mathrm{pF}, 200 \mathrm{pF}$, dan $300 \quad \mathrm{pF}$. Pengukuran dengan memvariasikan nilai kapasitansi dilakukan untuk memperoleh perbandingan nilai kapasintansi sehingga menghasilkan nilai induktansi yang nilai induktansi dari koil datar mengalami perubahan. Gambar 7 dan Gambar 8 menggambarkan hasil pengukuran dengan variasi nilai kapasitansi $\mathrm{C}_{0}[11]$.

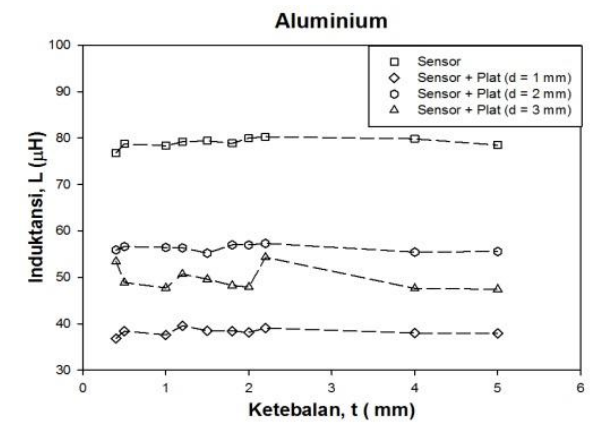

Gambar 7. Hasil pengukuran ketebalan pelat aluminium dengan variasi nilai kapasitansi.

Gambar 7 menggambarkan bahwa semakin besar nilai kapasitansi $\mathrm{C}_{0}$ yang digunakan maka nilai induktansi sensor yang diperoleh semakin kecil. Nilai induktansi pada masingmasing ketebalan dengan kapasitansi sebesar $100 \mathrm{pF}$ mengalami penurunan ketika nilai kapasitansinya berada pada 300 pF. Nilai kapasitansi yang kecil akan memperoleh nilai induktansi yang besar.

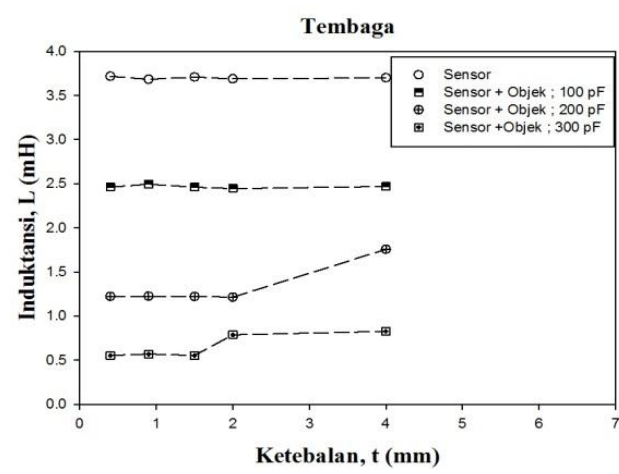

Gambar 8. Hasil pengukuran ketebalan pelat tembaga dengan variasi nilai kapasitansi. 
Gambar 8 menggambarkan bahwa semakin besar nilai kapasitansi $\mathrm{C}_{0}$ yang digunakan maka nilai induktansi sensor yang diperoleh semakin kecil. Nilai induktansi pada masingmasing ketebalan dengan kapasitansi sebesar $100 \mathrm{pF}$ mengalami saturasi ketika nilai kapasitansinya berada pada $300 \mathrm{pF}$. Ketebalan pada pengukuran untuk pelat tembaga Gambar 8 menjelaskan bahwa ketebalan tidak berpengaruh pada perubahan induktansi jika nilai kapasitansinya divariasikan.

\section{KESIMPULAN}

Berdasarkan hasil penelitian yang diperoleh dari pengukuran jarak aksial sensor koil datar menggunakan modul evaluation board LDC 1000 didapatkan beberapa kesimpulan sebagai berikut. Hubungan antara nilai induktansi dengan jarak pelat ke sensor koil datar pada aluminium kurang mempengaruhi dinyatakan dalam bentuk grafik dimana jarak d konstan 1 $\mathrm{mm}, 2 \mathrm{~mm}$, dan $3 \mathrm{~mm}$.Nilai induktansi diperoleh dari pengukuran ketebalan pelat berdasarkan hubungan antara induktansi dengan ketebalan pelat dengan menggunakanvariasi nilai kapasitansi. Hasil pengukuran ketebalan pelat dengan variasi kapasitansi menyimpulkan bahwa semakin besar nilai kapasitansi $\mathrm{C}_{0}$ yang digunakan dengan frekuensi sensor yang konstan sebesar $1 \mathrm{~Hz}$, maka nilai induktansi dari sensor koil datar berbentuk lingkaran akan semakin kecil. Pengukuran ketebalan pelat menggunakan modul EVB LDC 1000 memberikan hasil pengukuran dengan presisi yang tinggi dan sensitivitas jarak pelat dengan koil untuk pelat tembaga dan aluminum.

\section{REFERENSI}

1. $\mathrm{Du}, \mathrm{W}$. (2014). Resistive, Capacitive, Inductive, and Magnetic Sensor
Technologies. Boca Raton: CRC Press.

2. Horsky, P. (2005). LC Oscillator Driver for Safety Critical Applications. Proc. of DATE 05 Conference, Munich, Designers Forum, Germany, 5 Maret 2005, 34-38.

3. Decker, W. \& Kostka, P. (1989). Inductive and Eddy Current Sensors. In: Gopel, W., Hesse, J. and Zemel, J. N. (Eds.), Sensors: A Comprehensive Survey. Weinheim: VCH.

4. Benson, H. (1991). University Physics. U.S. America: John Wiley \& Sons.

5. Wilson, J. S. (2005). Sensor Technology Handbook. Newnes, Elsevier, USA.

6. Malik, U., Setiadi, Rahmondia, N., \& Umar, L. (2015). Sensor Planar Induktif Berbasis Bahan PCB FR-4 Untuk Pengukuran Jarak Kecil. Prosiding Seminar nasional Fisika Universitas Andalas (SNFU) 8 Oktober 2015, Padang, Sumatra Barat.

7. Texas Instrumen. (2014). LDC1000/LDC 1041/LDC1051 Evaluation Module. Diakses pada 14 Maret 2019, URL: http://www.ti.com/lit/pdf/snau150.

8. Mohan, S. S., del Mar Hershenson, M., Boyd, S. P., \& Lee, T. H. (1999). Simple Accurate Expressions for Planar Spiral Inductances. IEEE Journal OF Solid-state Circuits, 34(10), 1419-1424.

9. Halliday, D., Resnick, R., \& Walker, J. (1989). Fundamental of Physics. Canada: John Wiley \& Sons INC.

10. Jiles, D. (2015). Introduction to magnetism and magnetic materials. France: Taylor and Francis GroupCRC Press.

11. National Instruments. (2016). USB Instrument Control Tutorial. N.p., n.d. Web. Diakses pada 22 Maret 2019, URL: http://www.ni.com/tutorial/4478/en/.

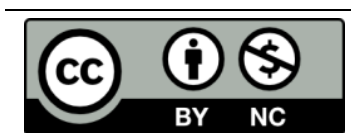

Artikel ini menggunakan lisensi

Creative Commons Attribution

4.0 International License 